\title{
Estudio sobre quimerismo reverso y el efecto de la movilización de células madre de médula ósea sobre la expresión de citouuinas en un modelo experimental de trasplante de tejidos compuestos \\ Study on reverse chimerism and the effect of mobilization of bone marrow stem cells on the expression of cytokines in an experimental model of composite tissue transplantation
}

\author{
Pedro BOLADO-GUTIÉRREZ*, Luis LANDÍN-JARILLO*, César CASADO-PÉREZ**
}

\section{Resumen}

Introducción y Objetivo. Los trasplantes de tejidos compuestos sufren rechazo crónico modulado entre otros factores por citoquinas. El quimerismo reverso o quimerismo del aloinjerto se define como la repoblación del tejido trasplantado por células circulantes del receptor. Plerixafor produce la movilización de células madre de médula ósea CD34+ hacia la sangre periférica.

El objetivo del estudio fue conocer los mecanismos moleculares que intervienen en el rechazo crónico y el quimerismo reverso tras la administración de plerixafor.

Material y Método. Realizamos 16 trasplantes osteomusculares heterotópicos de pata posterior entre ratas Brown-Norway hembra y Wistar Lewis macho bajo inmunosupresión subterapéutica con tacrólimus. Establecimos 2 grupos de estudio según la administración postoperatoria de plerixafor. Transcurridas 9 semanas estudiamos la expresión de citoquinas y el infiltrado leucocitario en distintas localizaciones musculares, así como el grado de rechazo crónico y porcentaje de quimerismo reverso en diferentes tejidos del aloinjerto.

Resultados. Encontramos diferencias estadísticas en la expresión de factor estimulante de colonias granulocíticas e interleucina 12 a nivel de los tercios medio y distal del aloinjerto, y de interleucina 6 a nivel del tercio medio del aloinjerto. La intensidad del infiltrado leucocitario fue mayor en el grupo que no recibió plerixafor. Ambos grupos desarrollaron rechazo crónico y pudimos observar la aparición de quimerismo reverso. Sin embargo no observamos diferencias significativas en el infiltrado leucocitario, el rechazo crónico ni el quimerismo reverso.

Conclusiones. La movilización de células madre de médula ósea CD34+ se asoció con una menor expresión de factor estimulante de colonias granulocíticas, interleucina 6 e interleucina 12. Estos hallazgos contribuyen a elucidar los mecanismos moleculares que podrían conducir a la creación de quimeras en el aloinjerto.
Background and Objective. Vascularized composite allotransplantation suffer chronic rejection modulated by cytokines. Reverse chimerism or allograft chimerism is defined as the repopulation of the transplanted tissue by circulating cells of the recipient. Plerixafor mobilizes CD34+ bone marrow stem cells to the peripheral blood.

The aim of the study was to know the molecular mechanisms involved in chronic rejection and reverse chimerism after plerixafor administration

Methods. Sixteen heterotopic osteomuscular hindlimb transplants were performed between female Brown-Norway rats as donors and male Wistar Lewis rats as recipients under subtherapeutic immunosuppression with tacrolimus. Two groups were established according to the postoperative administration of plerixafor. After 9 weeks, expression of cytokines and leukocyte infiltration were studied in different muscle locations, as well as the degree of chronic rejection and percentage of reverse chimerism in different tissues of the allograft

Results. Statistical differences were found in granulocyte colony stimulating factor and interleukin 12 expression at middle and distal allograft thirds, and interleukin 6 expression at middle allograft third. The intensity of leukocyte infiltration was greater in the group that did not receive plerixafor. Both groups developed chronic rejection and the appearance of reverse chimerism could be observed. However, no significant differences were observed in leukocyte infiltration, chronic rejection or reverse chimerism.

Conclusions. The mobilization of CD34+ bone marrow stem cells was associated with a lower expression of granulocytic colony stimulating factor, interleukin 6 and interleukin 12 .

These findings contribute to elucidate the molecular mechanisms that could lead to the creation of chimeras in the allograft.

Ayudas recibidas: Trabajo incluido en el Proyecto de Investigación en Salud "Protocolo de inmunosupresión reducida tras condicionamiento con precursores hematopoiéticos en trasplantes de tejidos compuestos: Investigación básica y clínica”, con número de expediente PI12/00867, y cofinanciado por el Instituto de Salud Carlos III (ISCIII) y el Fondo Europeo de Desarrollo Regional (FEDER).
Palabras clave Trasplante tejidos compuestos, Rechazo crónico, Quimerismo reverso, Células madre médula ósea CD34+, Plerixafor.
Nivel de evidencia científica 4 Investigación Básica
Recibido [esta versión]
27 noviembre/2017
Aceptado

\begin{tabular}{|lc|}
\hline Key words & $\begin{array}{l}\text { Vascularized composite allotransplantation, } \\
\text { Chronic rejection, Reverse chimerism, } \\
\text { CD34+ bone marrow stem cell, Plerixafor }\end{array}$ \\
Level of evidence & 4 Bench Research \\
Received lthis version] & 27 november $/ 2017$ \\
Accepted & 23 may/2018
\end{tabular}

Facultativo Especialista de Área.

** Jefe del Servicio.

Servicio de Cirugía Plástica, Reparadora y Quemados, Hospital Universitario La Paz, Madrid, España.

Trabajo galardonado con el Premio Nacional de Residentes de la Sociedad Española de Cirugía Plástica, Reparadora y Estética (SECPRE) en su LI Congreso Nacional celebrado en Estoril, Portugal, junio de 2016; y con el Primer Premio de Investigación Experimental en el Concurso Internacional de Residentes de la Federación Ibero-Latinoamericana de Cirugía Plástica (FILACP) en su XXII Congreso celebrado en Lima, Perú, mayo de 2018. 


\section{Introducción}

En los trasplantes de tejidos compuestos (TTCs) se transfieren tejidos vascularizados antigénicamente heterogéneos. Los TTCs de miembros están formados por la piel, el tejido subcutáneo, nervioso, muscular, tendinoso, fascial, cartilaginoso, óseo y la médula ósea vascularizada (MOV).

Los protocolos convencionales de inmunosupresión (IS) mantienen al receptor en un "estado de ignorancia" frente al aloinjerto y contribuyen al éxito clínico del trasplante. La IS puede prevenir o revertir los episodios de rechazo agudo (RA). Sin embargo, el aloinjerto sigue expuesto a la aparición de rechazo crónico (RC) o vasculopatía crónica del aloinjerto. El RC se caracteriza por vasculopatía fibroproliferativa y fibrosis tisular del órgano trasplantado. La estenosis de la luz vascular puede producirse por un engrosamiento difuso y concéntrico de la íntima conocido como hiperplasia intimal, o por una fibrosis de la adventicia. ${ }^{(1)}$ Las lesiones histopatológicas del RC son en gran medida irreversibles y producen progresivamente la disfunción del aloinjerto. ${ }^{(1)} \mathrm{Si}$ bien se desconoce la relación exacta entre el RA y el RC y los mecanismos moleculares que los regulan, los episodios de RA aceleran el desarrollo de RC tanto en trasplante de órgano sólido (TOS) como en modelos de TTC. . $^{(1,2)}$ Los fenómenos de RC pueden observarse en modelos experimentales de trasplante cuando se utiliza IS a dosis sub-terapéuticas. ${ }^{(3)}$

La MOV que aportan los huesos de los aloinjertos en los TTCs se integra en el espacio vascular del receptor tras la revascularización del aloinjerto. ${ }^{(4)}$ Las células madre de médula ósea (CMMO) del donante generan un estado de quimerismo sistémico en la sangre periférica, la médula ósea y los tejidos linfoides del receptor que puede contribuir a la inducción de tolerancia específica frente al donante. ${ }^{(5)}$ La tolerancia del trasplante podría definirse como la falta de respuesta inmunitaria del receptor frente a antígenos específicos del donante sin la necesidad de IS crónica para su mantenimiento, preservando intacta la respuesta inmunitaria frente al resto de los antígenos. ${ }^{(5)}$ Los linfocitos derivados de las CMMO del donante pueden contribuir a prolongar la supervivencia a largo plazo del aloinjerto mediante la regulación negativa de la respuesta inmunitaria del receptor específica frente al donante. ${ }^{(6)}$

El tráfico celular desde el receptor hacia el aloinjerto puede producirse mediante un fenómeno conocido como quimerismo reverso $(\mathrm{QR})$ o quimerismo del aloinjerto. El QR consiste en la repoblación del aloinjerto por células del receptor. Hasta el momento se desconoce qué tipos de células son las responsable de la producción de QR, así como los mecanismo moleculares que lo regulan en los TTCs..$^{(7)}$ Sin embargo, se especula que las CMMO del receptor en sangre periférica y que circulan a través del aloinjerto podrían diferenciarse en los diferentes fenotipos celulares que lo componen. ${ }^{(8)}$
El factor derivado del estroma 1 (SDF-1; CXCL12) es una citoquina multifuncional que pertenece a la familia de quimiocinas CXC y se expresa de forma constitutiva en células del estroma de la médula ósea (MO). El receptor de SDF-1, CXCR4, se expresa en diferentes tipos celulares entre los que se encuentran las CMMO $\mathrm{CD}^{+} 4^{+}$que juegan un papel crítico en la supervivencia, proliferación, migración y mantenimiento celular. ${ }^{(9)} \mathrm{Ple}$ rixafor es un fármaco antagonista del receptor alfa de la citoquina CXCR4 e impide la unión de SDF-1. Su administración produce la movilización de CMMO a sangre periférica. Por este motivo se ha utilizado en casos de linfoma y mieloma múltiple de tal manera que las CMMO CD $34^{+}$puedan extraerse, conservarse e infundirse de nuevo tras la finalización de tratamientos mieloablativos.

El objetivo del estudio fue evaluar la expresión de citoquinas en un modelo experimental de RC en aloinjertos osteomusculares heterotópicos de pata posterior de rata, sometidos a IS subterapéutica con tacrólimus, tras la movilización de CMMO CD34+ con plerixafor. Además se establecieron los siguientes objetivos secundarios: analizar el infiltrado leucocitario cualitativamente y cuantitativamente en el tercio medio del tejido muscular del aloinjerto, el grado de $\mathrm{RC}$ en los vasos femorales y del tercio medio y distal del tejido muscular del aloinjerto, y el porcentaje de $\mathrm{QR}$ en la $\mathrm{MO}$ del aloinjerto.

\section{Material y método}

\section{Protocolo quirúrgico experimental}

Todos los animales recibieron un trato adecuado de acuerdo a la Directiva del Consejo de Europa del 22 de septiembre de 2010 (2010/63/UE). El proyecto fue aprobado por el Comité Ético de Bienestar Animal del Hospital Universitario La Paz (Madrid, España) con fecha 27 de febrero de 2012.

Realizamos 16 transferencias de pata posterior entre ratas (Rattus Norvergicus) de 2 familias no consanguíneas: ratas macho Wistar-Lewis (LEW) haplotipo RT $1^{1}$ como receptoras y ratas hembra Lewis Brown-Norway (LBN) RT1 ${ }^{\text {n }}$ como donantes (Janvier Labs, Le Genest-Saint-Isle, Francia), divididas en 2 grupos de experimentación con 8 animales en cada grupo. Todos los animales fueron sometidos a trasplante inmediato y posterior IS subterapéutica con tacrólimus (Prograf ${ }^{\circledR}$, Astellas Pharma, Chūō, Tokyo, Tokio, Japón). El grupo II además fue sometido a terapia movilizadora de CMMO CD34+ ${ }^{+}$con plerixafor $\left(\right.$Mozobil $^{\circledR}$, Genzyme, Cambridge, Massachusetts, EE.UU.) (Tabla I).

\section{Extracción del aloinjerto}

El aloinjerto se extrajo a nivel de la raíz de la pata posterior de la rata, tomando los vasos femorales como pedículo (Fig. 1).

\section{Técnica quirúrgica en el animal receptor}

En la rata receptora disecamos los vasos femorales 
Tabla I. Grupos de experimentación

\begin{tabular}{|c|c|c|c|c|c|}
\hline Grupo & $\mathbf{n}$ & Donante $\Rightarrow$ Receptor & Terapia IS (días) & $\begin{array}{c}\text { Terapia movilizadora de } \\
\text { CMMO CD34 }^{+} \text {(días) }\end{array}$ & Supervivencia (días) \\
\hline I & 8 & Hembra $\Rightarrow$ Macho & $\begin{array}{c}\text { Tacrólimus } 0.1 \mathrm{mg} / \mathrm{kg} \\
(0,1,2,3,7 \text { post-trasplante })\end{array}$ & No & 63 \\
\hline II & 8 & Hembra $\Rightarrow$ Macho & $\begin{array}{c}\text { Tacrólimus } 0.1 \mathrm{mg} / \mathrm{kg} \\
(0,1,2,3,7 \text { post-trasplante })\end{array}$ & $\begin{array}{c}\text { Plerixafor } 1 \mathrm{mg} / \mathrm{kg} \\
(0,1,2,3,7 \text { post-trasplante })\end{array}$ & 63 \\
\hline
\end{tabular}

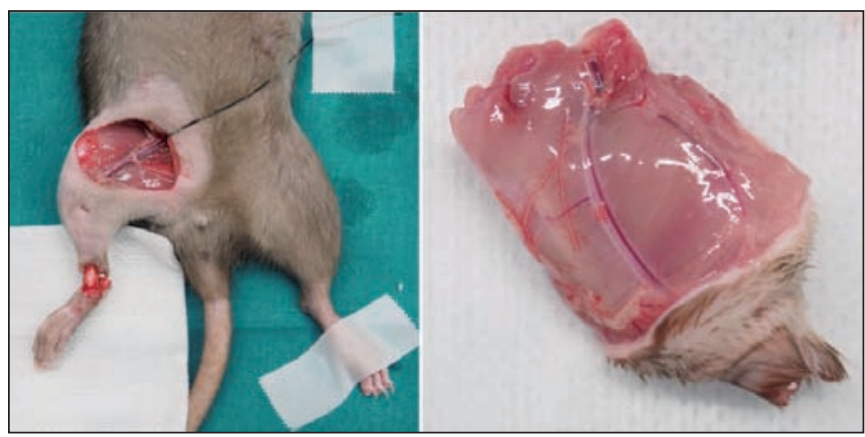

Fig. 1. Extracción del aloinjerto. Izquierda: disección de los vasos femorales a nivel de la ingle y de los vasos tibiales anteriores y posteriores a nivel del tobillo. Derecha: extracción del aloinjerto.

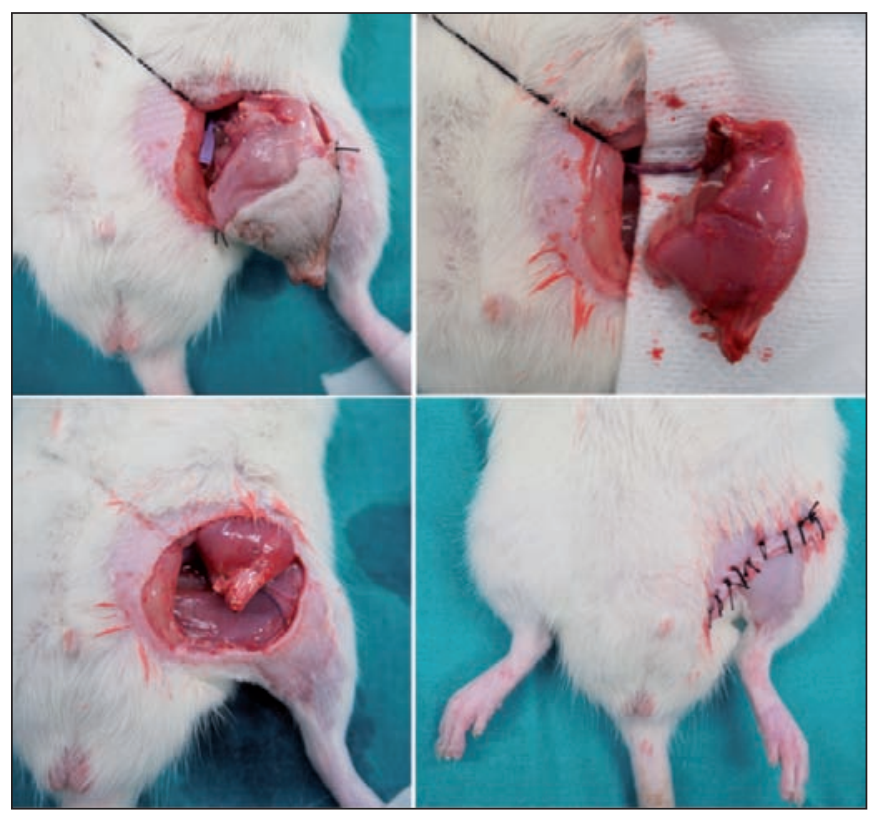

Fig. 2. Técnica quirúrgica en el animal receptor. Superior izquierda: fijación del aloinjerto. Superior derecha: desepidermización del aloinjerto tras patencia vascular positiva. Inferior izquierda: acomodación heterotópica subcutánea abdominal del aloinjerto. Inferior derecha: cierre de la zona receptora.

como vasos receptores. Las anastomosis arterial y venosa las realizamos mediante técnica término-terminal. Tras comprobar la patencia vascular del aloinjerto procedimos a la eliminación de la totalidad del componente cutáneo y posterior acomodación heterotópica subcutánea a nivel abdominal (Fig. 2).

\section{Protocolo de inmunosupresión}

Todos los animales receptores recibieron terapia IS subterapéutica con tacrólimus (Prograf ${ }^{\circledR}$, Astellas Pharma, Chūō, Tokyo, Tokio, Japón) a dosis de 0,1 $\mathrm{mg} / \mathrm{kg} / 24$ horas por vía subcutánea los días 0 , 1, 2, 3 y 7 post-trasplante. ${ }^{(10)}$

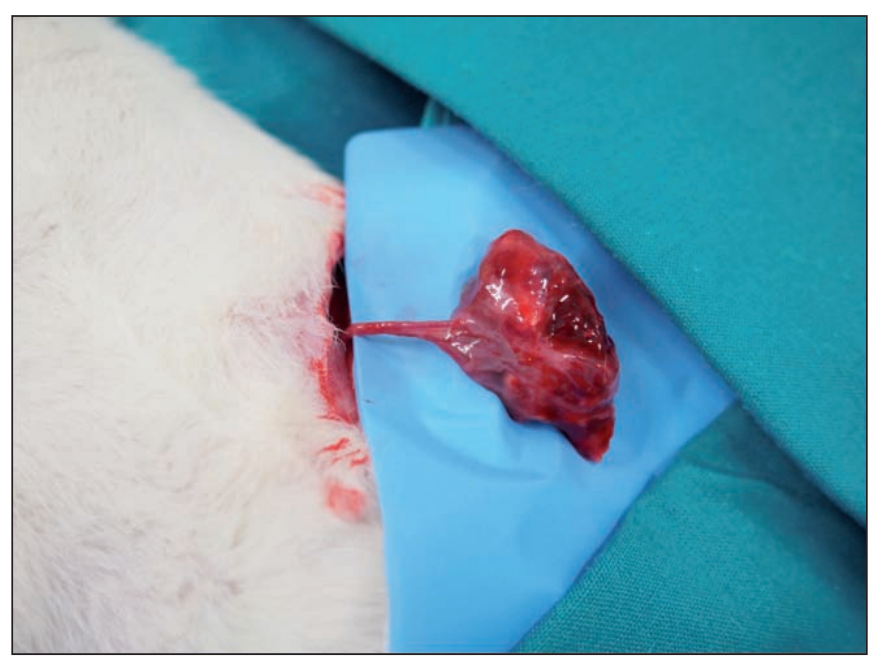

Fig. 3. Extracción del aloinjerto a las 9 semanas post-trasplante.

\section{Protocolo de movilización de CMMO CD34+}

Los animales receptores del grupo II recibieron terapia movilizadora de CMMO CD34+ ${ }^{+}$con plerixafor (Mozobil $^{\circledR}$, Genzyme, Cambridge, Massachusetts, EE.UU.) a dosis de $1 \mathrm{mg} / \mathrm{kg} / 24$ horas por vía subcutánea los días 0 , $1,2,3$ y 7 post-trasplante. ${ }^{(10)}$

\section{Seguimiento clínico}

En todos los animales monitorizamos la evolución ponderal semanal y la aparición de signos de enfermedad injerto contra huésped (EICH) entre los que incluímos la aparición de lesiones cutáneas, alopecia, atrofia muscular, dificultad respiratoria, diarrea o debilidad generalizada. Toda lesión cutánea sospechosa fue evaluada anatomopatológicamente.

\section{Protocolo de extracción de los aloinjertos}

Transcurridas 9 semanas post-trasplante recuperamos los aloinjertos para su procesado y análisis (Fig. 3). Posteriormente sacrificamos los animales receptores.

\section{Procesado y estudio de las muestras}

Dividimos los aloinjertos en fresco en diferentes muestras que comprendían los vasos femorales, la tibia y el tejido muscular y los fijamos en tampón formalina. Las muestras musculares las dividimos en tercios con preservación exclusiva de los tercios medio y distal.

\section{Valoración de la expresión de citoquinas}

Realizamos mediciones en los tercios medio y distal del tejido muscular del aloinjerto utilizando el panel de 
22 citoquinas del sistema ProcartaPlex ${ }^{\mathrm{TM}}$ Multiplex Immunoassays (Affymetrix, Santa Clara, California, EE.UU.) según instrucciones del fabricante. Las citoquinas incluidas en el panel seleccionado fueron: Eotaxina, oncogén relacionado con el crecimiento $\alpha$ (GRO- $\alpha$ ), factor estimulante de colonias de granulocitos (G-CSF), factor estimulante de colonias de granulocitos y monocitos (GM-CSF), interferón $\gamma$ (IFN- $\gamma$ ), interleucina $1 \alpha$ (IL-1 $\alpha$ ), IL-1 $\beta$, IL-2, IL-4, IL-5, IL-6, IL-10, IL-12, IL-13, IL$17 \mathrm{~A}, \mathrm{IFN}-\gamma$-proteína inducible 10 (IP-10), proteína quimiotáctica de monocitos 1 (MCP-1), MCP-3, proteína inflamatoria de macrófagos $1 \alpha$ (MIP-1 $\alpha$ ), MIP-2, quimiocina expresada y secretada por células T normales reguladas tras la activación (RANTES) y factor de necrosis tumoral $\alpha$ (TNF- $\alpha$ ). Tras el procesado de las muestras e incubación por duplicado con cada uno de los anticuerpos frente a las citoquinas de interés, cuantificamos la señal obtenida en el panel mediante un analizador Luminex xMAP 200 (Luminex Corporation, Austin, Texas, EE.UU.).

\section{Valoración del infiltrado leucocitario}

- Cualitativa. Realizamos una valoración subjetiva del infiltrado leucocitario en muestras del tercio medio del tejido muscular con tinción de hematoxilina-eosina (Merck KGaA, Darmstadt, Alemania) y una magnificación de x100. El muestreo lo llevaron a cabo 2 observadores independientes en 5 cortes seleccionados de manera aleatoria para cada aloinjerto. La escala utilizada fue: $0=\mathrm{Au}-$ sencia; 1 = Leve; 2 = Moderado; 3 = Intenso.

- Cuantitativa. Realizamos un estudio inmunohistoquímico (IHQ) de los antígenos leucocitarios CD3, CD4, CD8, CD20 y CD68 a nivel del tercio medio del tejido muscular del aloinjerto con el objetivo de identificar los subtipos celulares. Para ello desenmascaramos los antígenos leucocitarios con un protocolo ajustado para cada anticuerpo primario mediante el sistema PTLink Dako ${ }^{\circledR}$ (PreTreatment). El equipo de tinción empleado fue el Autostainer Plus de Dako ${ }^{\circledast}$ siguiendo las recomendaciones del fabricante. Los resultados mostraron los núcleos celulares en azul-violeta y las células positivas en marrón.

Escogimos 5 cortes aleatorios por aloinjerto y muestreamos 2 áreas de $90000 \mu \mathrm{m}^{2}$ por corte, con una magnificación de x200. Consideramos positivas para el contaje aquellas células que mostraban núcleo y citoplasma. El muestreo se llevó a cabo por 2 observadores independientes (Fig. 4).

\section{Valoración del rechazo crónico}

Valoramos el RC en los vasos de femorales y en los vasos del tercio medio y distal del tejido muscular del aloinjerto mediante la medición de la proliferación intimal (PI) y el porcentaje de permeabilidad arterial (PPA):

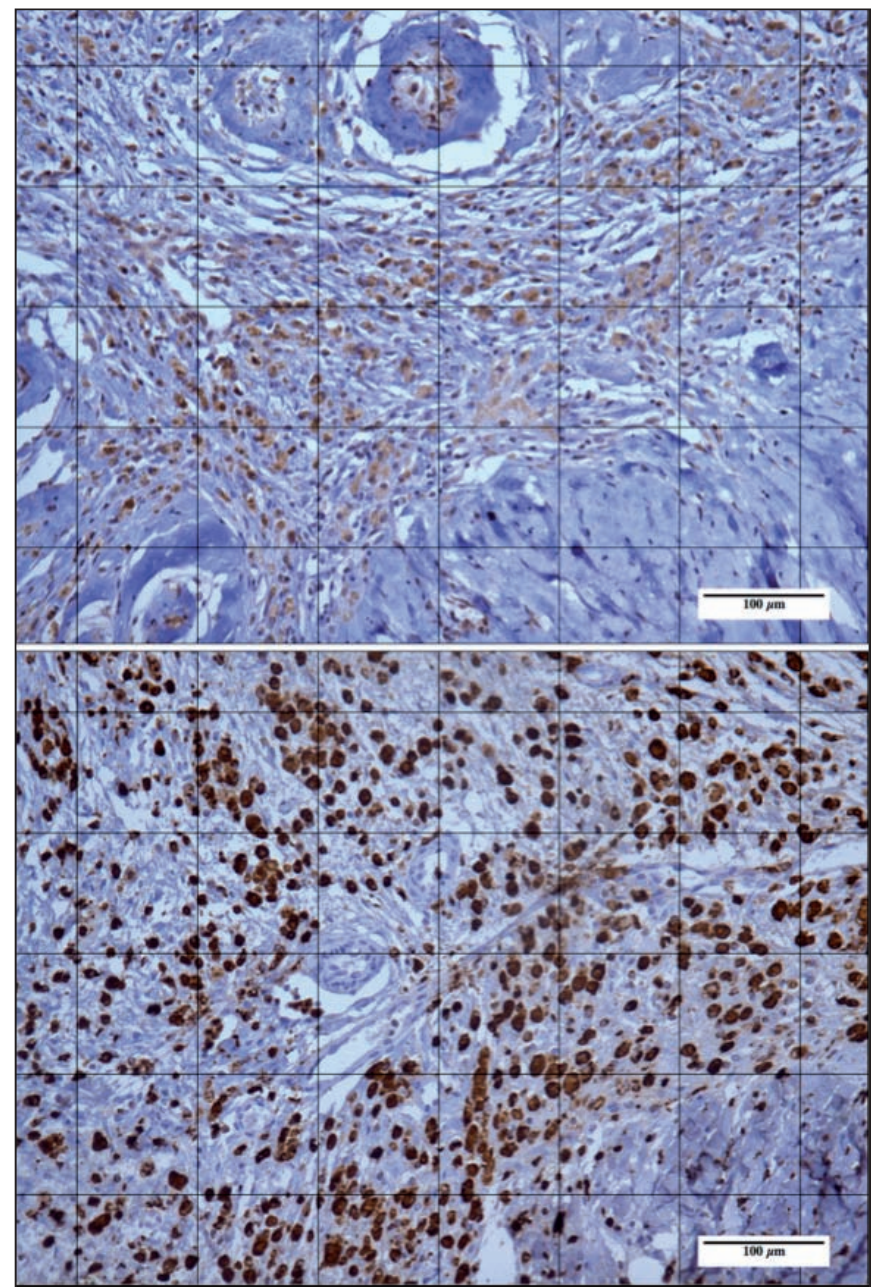

Fig. 4. Valoración cuantitativa del infiltrado leucocitario. Superior: tinción IHQ CD4 (x200). Inferior: tinción IHQ CD68 (x200).

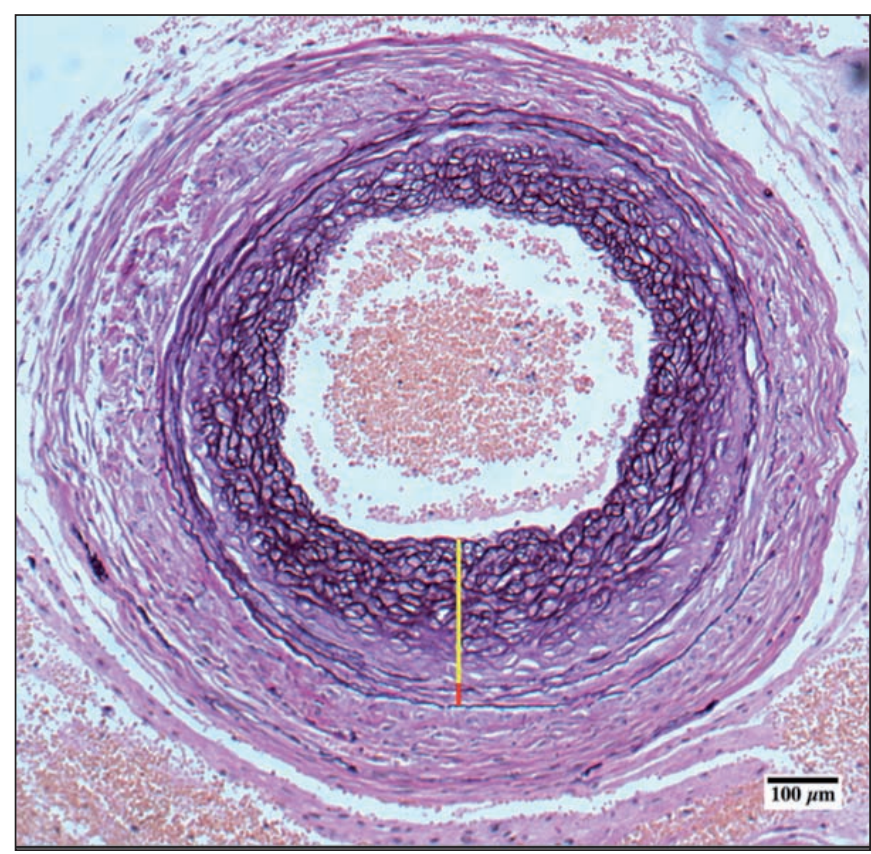

Fig. 5. Valoración de la PI en vasos femorales tras tinción de fibras elásticas según van Gieson (x100). Línea amarilla: intima. Línea roja: media.

- PI (Fig. 5): porcentaje del grosor total de la pared arterial que ocupa la íntima. Obtenido según la fórmula (Íntima / (Íntima + Media)) x 100. 
- PPA (Fig. 6): porcentaje de la luz arterial que es permeable al flujo y no ha sido ocupada por la neoíntima. Obtenido según la fórmula (Área de la neoíntima / Área de la lámina elástica interna) x 100.

Para ello preparamos 5 cortes histológicos aleatorios de cada segmento vascular a estudiar, y valoramos tras tinción con el kit de tinción de fibras elásticas según van Gieson (Merck KGaA, Darmstadt, Alemania). Los resultados mostraron los núcleos celulares de color pardo negruzco, las fibras elásticas en negro, el colágeno en rojo y la musculatura en amarillo.

\section{Valoración del quimerismo reverso}

Evaluamos la repoblación celular de la MO del aloinjerto mediante el análisis del porcentaje de células con cromosoma $\mathrm{Y}$ en el aloinjerto con técnica Real-Time PCR (RT-PCR), mezclando SYBR ${ }^{\circledR}$ Green PCR Master Mix (Thermo Fisher Scientific, Waltham, Massachusetts,

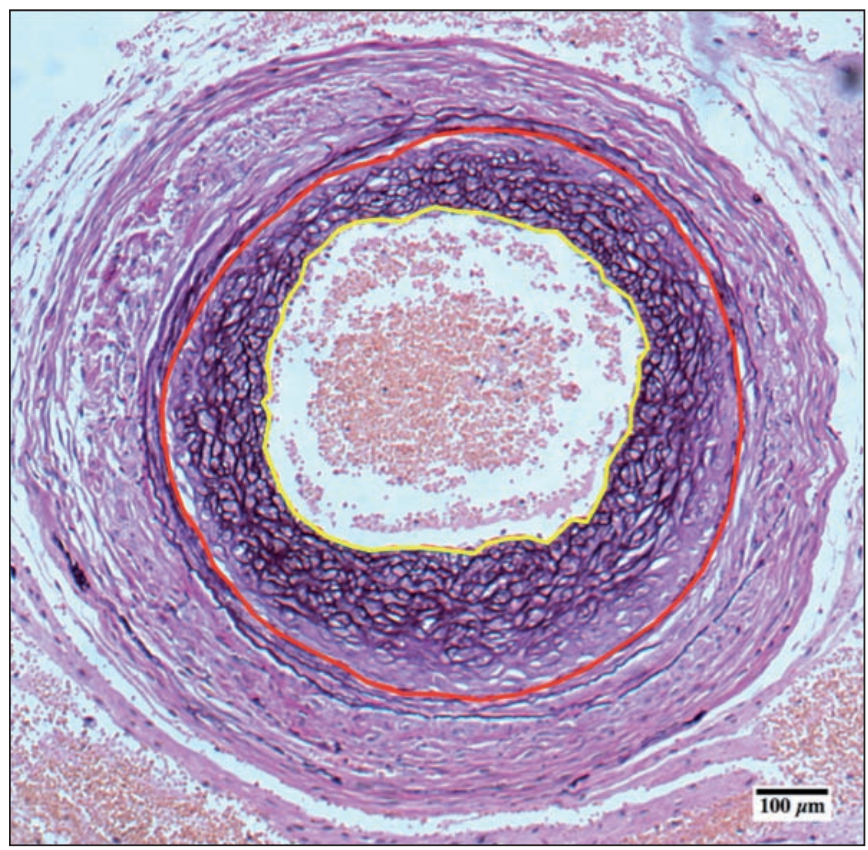

Fig. 6. Valoración del PPA en vasos femorales tras tinción de fibras elásticas según van Gieson (x100). Línea amarilla: área de la neoíntima. Línea roja: área de la lámina elástica interna.
EE.UU) con los cebadores murinos Bcl-2 del cromosoma 13 y Sry del cromosoma Y, y el ADN genómico a estudiar, realizando el análisis por triplicado.

\section{Análisis estadístico}

Realizamos el análisis estadístico utilizando el programa SAS 9.3 (SAS Institute, Cary, Carolina del Norte, EE.UU.). Todas las pruebas estadísticas se han considerado bilaterales y como valores significativos aquellos que presentaron una probabilidad de error menor del 5\% ( $\mathrm{p}<0.05)$.

Realizamos la comparación entre grupos de los valores de citoquinas y de QR usando el test de la U de MannWhitney (no paramétrico para datos independientes).

La comparación entre grupos de los valores de infiltrado inflamatorio y de PI y PPA en los vasos femorales y musculares del aloinjerto, teniendo en cuenta las diferentes replicaciones de dichos parámetros en los mismos sujetos, la analizamos mediante un modelo de regresión lineal con efectos mixtos, con las replicaciones y el grupo (I frente a II) como factores.

\section{RESULTADOS}

\section{Supervivencia y seguimiento clínico}

La supervivencia global fue del $84.21 \%$, con 16 ratas viables de 19 operadas. El tiempo medio de la intervención fue de 191.32 minutos (130 - 250 minutos), con un tiempo medio de microcirugía de 82.90 minutos (120 60 minutos). De los 3 animales no viables, 2 murieron en el postoperatorio inmediato debido a parada cardiorrespiratoria en probable relación con la pérdida hemática producida durante la cirugía, y el tercero fue sacrificado el día 28 post-trasplante debido a infección tardía de la herida quirúrgica con empeoramiento del estado general. No observamos signos de EICH.

\section{Resultados de la expresión de citoquinas}

Las concentraciones de citoquinas con diferencias significativas a nivel del tercio medio y distal del aloinjerto están representadas en diagrama Box-Plot en las Fig. 7-9.

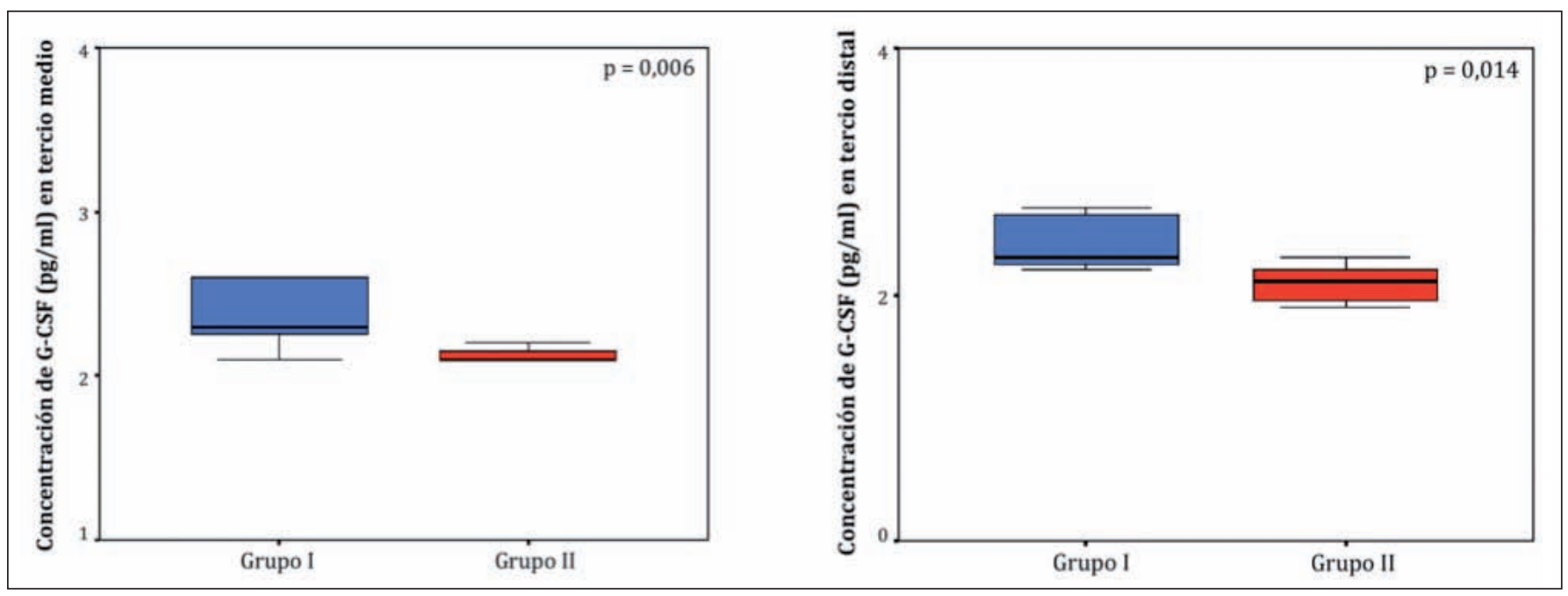

Fig. 7. Representación Box-Plot de la concentración de G-CSF en tercios medio y distal. 


\section{Resultados del infiltrado leucocitario}

- Cualitativa. El infiltrado leucocitario medio del grupo I fue intenso mientras que en grupo II fue moderado (Fig. 10).

- Cuantitativa. Los resultados de los contajes celulares en el tercio medio del aloinjerto por área media de $90000 \mu \mathrm{m} 2$ con una magnificación de $\times 200$ para los estudios IHQ frente a los antígenos CD3, CD4, CD8, CD20 y CD68 están representados en la Fig. 11. No encontramos diferencias significativas entre ambos grupos.

\section{Resultados del rechazo crónico}

Todas las muestras estudiadas presentaron signos histopatológicos de RC. Los resultados de cada una de las muestras a nivel de los vasos femorales y de los vasos del tercio medio y distal del aloinjerto expresados como PI y PPA están representados en las Fig. 12 y 13. No encontramos diferencias significativas entre ambos grupos.

\section{Resultados del quimerismo reverso}

El porcentaje medio de QR en el grupo I y en el grupo

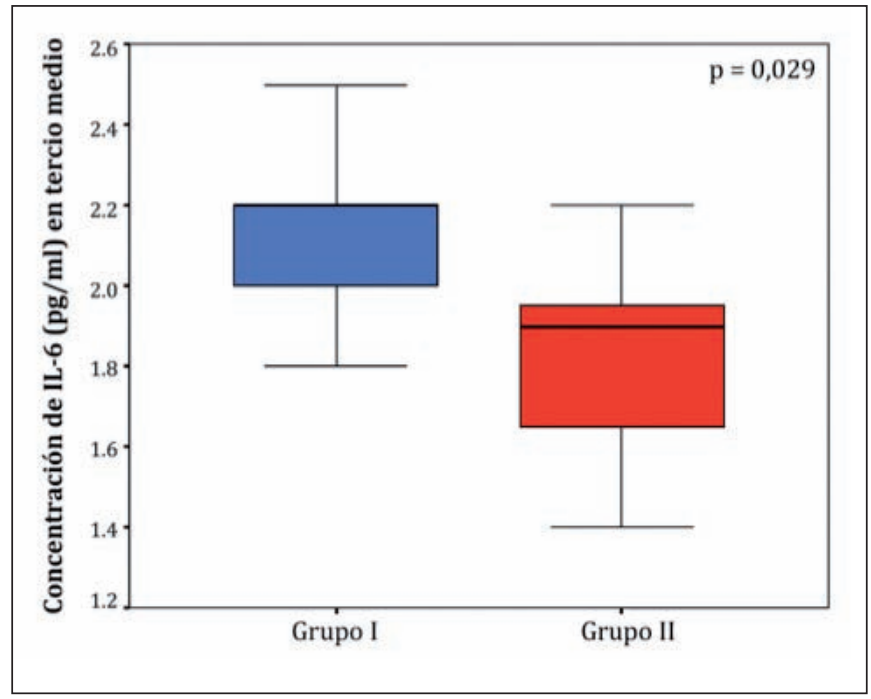

Fig. 8. Representación Box-Plot de la concentración de IL-6 en tercio medio.
II fue $85.61 \% \pm 16.41 \%$ y $88.40 \% \pm 16.97 \%$, respectivamente (Fig. 14). No encontramos diferencias significativas entre ambos grupos.

\section{Discusión}

Las CMMO del donante tienen un efecto inmunorregulador favoreciendo la tolerancia del aloinjerto tras la producción de quimerismo sistémico hematopoyético en el receptor. ${ }^{(11)}$ Se ha hipotetizado que el QR también podría promover la aceptación del aloinjerto por el receptor. ${ }^{(12)}$ Entre los mecanismos moleculares que regulan el rechazo y la tolerancia del aloinjerto se encuentran las citoquinas. ${ }^{(13)}$ Sin embargo, se desconoce el patrón específico de expresión de citoquinas tras un TTC así como su relación con el RC y el QR ${ }^{(13)}$ Nuestros resultados muestran la presencia de RC y QR en $\mathrm{MO}$ en todos los aloinjertos. Además, la expresión de citoquinas en el tejido muscular del aloinjerto muestra una disminución significativa de G-CSF, IL-6 e IL-12. Estos cambios en el patrón de expresión de citoquinas podrían deberse al efecto regulador de la respuesta inmunitaria de las CMMO CD34 ${ }^{+}$movilizadas por plerixafor.

La transferencia de células de MO a través de los aloinjertos óseos vascularizados y los TTCs de miembros favorece la producción de quimerismo sistémico linfohematopoyético en el receptor, lo que se ha relacionado con una regulación negativa de la respuesta inmunitaria frente al aloinjerto y la supervivencia a largo plazo del tejido trasplantado. ${ }^{(11)}$

La falta de homogeneidad en el diseño de los estudios experimentales y clínicos de TOS y TTCs es uno de los problemas que impide establecer un patrón específico de expresión de citoquinas en el aloinjerto ni relacionarlo directamente con el rechazo y la tolerancia. ${ }^{(14)} \mathrm{Se}$ ha sugerido que la respuesta de los linfocitos T helper 1 (Th1) podría relacionarse con los episodios de rechazo, mientras que los linfocitos Th2 podrían estar involucradas en la generación de estados de tolerancia. ${ }^{(15)} \mathrm{Wu}$ y col. ob-
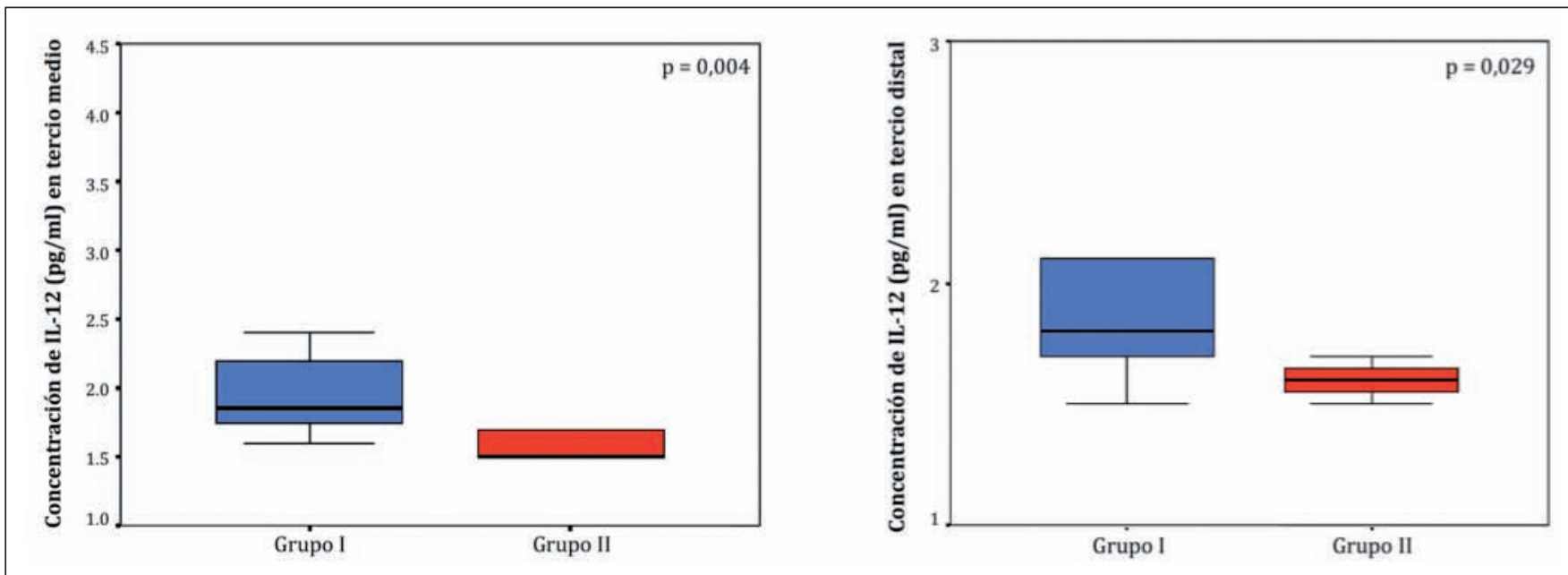


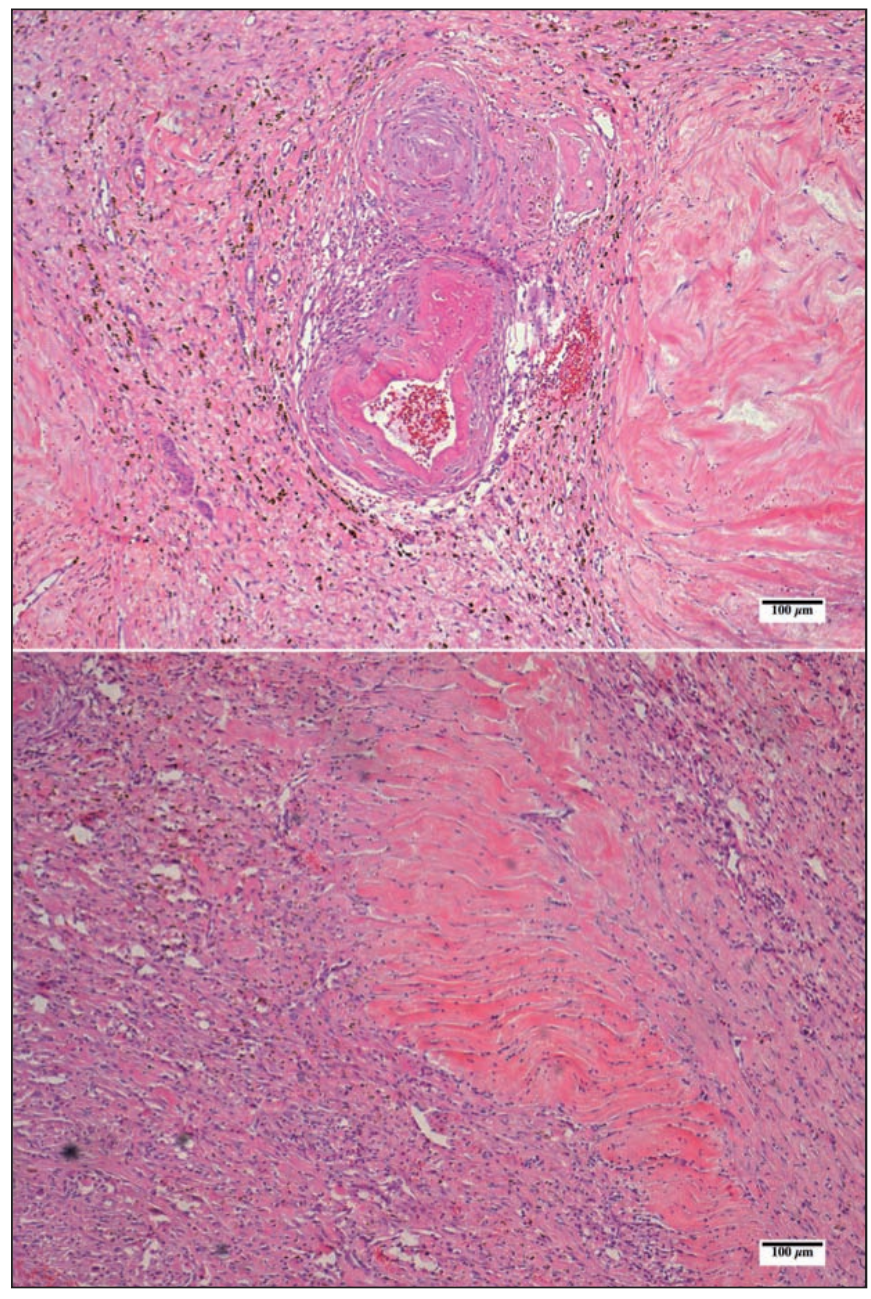

Fig. 10. Superior: infiltrado leucocitario de grado moderado. Tinción hematoxilina-eosina (x100). Inferior: infiltrado leucocitario de grado intenso. Tinción hematoxilina-eosina (x100).

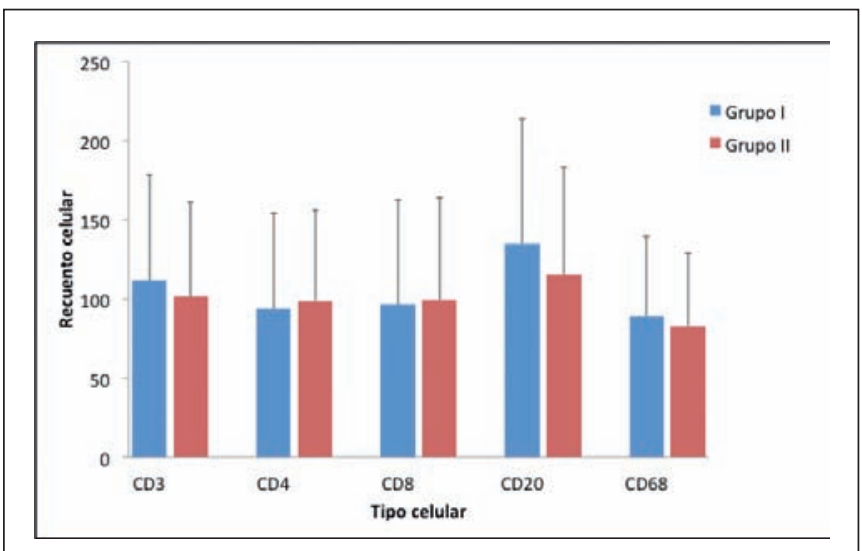

Fig. 11. Resultados de los contajes celulares en el tercio medio del aloinjerto.

servaron una mayor expresión de IL-1 $\beta$, IL-2, IL-6, IFN$\gamma$ y TNF- $\alpha$ en aloinjertos cardiacos con rechazo. ${ }^{(16)}$ Van Hoffer y col. demostraron niveles aumentados de IL-2, IL-3, IL-6, IL-8, IL-10 e IL-12 en aloinjertos cardiacos de pacientes con rechazo. ${ }^{(17)}$ De Mattos y col. identificaron expresión de IL-12 en aloinjertos renales durante los episodios de RA. ${ }^{(18)}$ No hay evidencia acerca de los niveles de expresión de G-CSF en los aloinjertos de TOS ni de TTCs. Sin embargo, Vrtovec y col. concluyeron que la administración exógena de G-CSF parecía estar asociada

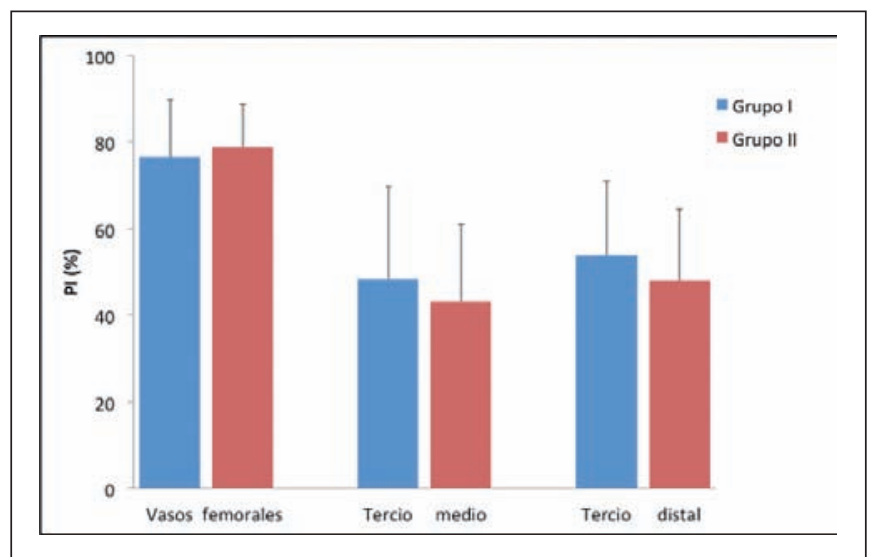

Fig. 12. Resultados de la PI en los vasos femorales y en los tercio medio y distal del aloinjerto.

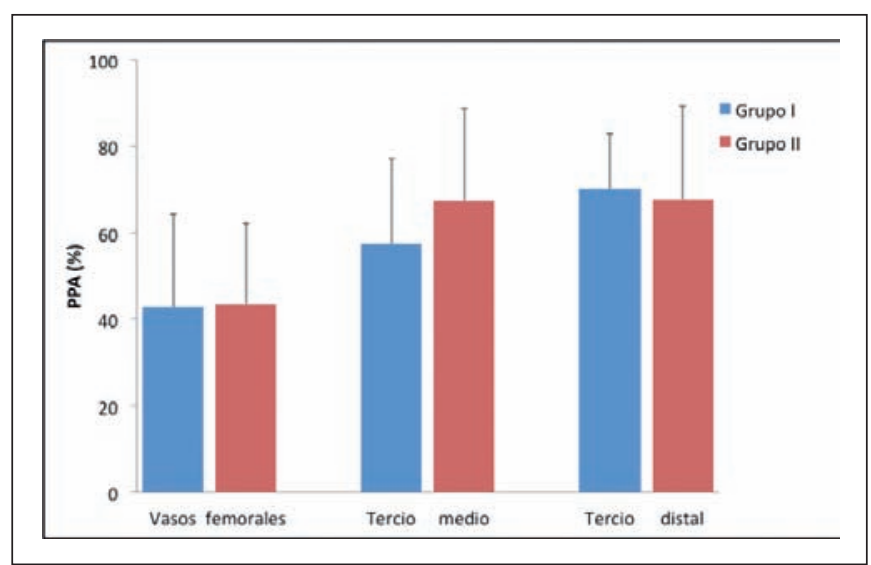

Fig. 13. Resultados del PPA en los vasos femorales y en los tercio medio y distal del aloinjerto.

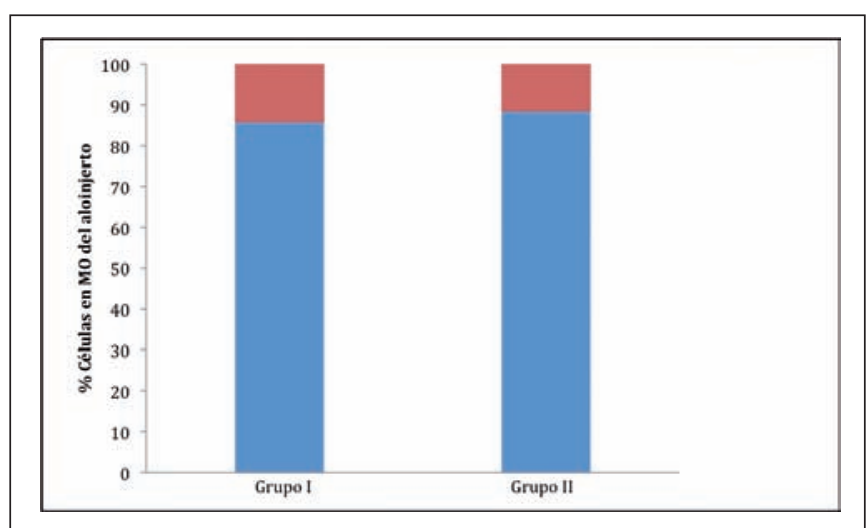

Fig. 14. QR en MO del aloinjerto expresado como porcentaje de células de receptor y del donante.

con una menor incidencia de RA y RC en aloinjertos cardiacos, sugiriendo un potencial efecto modulador de la respuesta inmunitaria..$^{(19)}$

La regeneración celular del aloinjerto puede activarse para reparar los tejidos lesionados por la respuesta inmunitaria del receptor y la lesión por isquemia y reperfusión. ${ }^{(13)}$ Además, en los TTCs de miembros esta agresión se ve agravada por la osteotomía y la denervación del aloinjerto. ${ }^{(20)}$ Diferentes autores como Olthoff o Miyake han sugerido que las citoquinas, la activación de factores de transcripción y la expresión de genes moduladores del ciclo celular están implicados en los meca- 
nismos de regeneración celular. ${ }^{(21,22)}$ Olthoff estudió los mecanismos de regeneración celular en aloinjertos hepáticos observando que las células de Kupffer son una fuente primaria de IL-6 y factores de crecimiento tras el trasplante, implicados en el inicio de la regeneración hepática. ${ }^{(13)}$

La disminución significativa de IL-6 e IL-12 en los aloinjertos del grupo sometido a tratamiento movilizador de $\mathrm{CMMO} \mathrm{CD} 34^{+}$con plerixafor observada en nuestros resultados podría estar relacionada con la presencia de un menor número de episodios de RA asociado al efecto modulador de la respuesta inmunitaria producido por las CMMO circulantes. Además, si suponemos que el daño tisular generado por los episodios de rechazo ha sido superior en el grupo no sometido a tratamiento movilizador de CMMO CD $34^{+}$con plerixafor, los valores de IL-6 también podrían verse incrementados como señal de una mayor regeneración tisular.

Diferentes teorías centradas en el QR intentan explicar el proceso que hace que el aloinjerto sea gradualmente menos inmunogénico. Medawar fue el primero en hipotetizar que la aceptación del aloinjerto podría ser el resultado del reemplazo endotelial de las células del aloinjerto por las del receptor, lo que se conoce como QR endotelial. ${ }^{(12,23)}$ Sin embargo, la función del aloinjerto depende de células especializadas que también pueden ser objeto de reemplazo, lo que se conoce como QR órgano específico. ${ }^{(23)}$ Muramatsu y col. evidenciaron histológicamente en TTCs en ratas valorados a los 18 meses posttrasplante que el QR se producía gradualmente en la piel, el endotelio y la MO, pero la mayor del parte del periostio y del tejido muscular seguía estando formado por células del donante. ${ }^{(24)}$ Mathes y col. encontraron que el QR en MO de TTCs en cerdos era progresivo y llegaba a ser completo a las 48 semanas post-trasplante. ${ }^{(25)}$ Nuestros resultados muestran unos porcentajes de $\mathrm{QR}$ en $\mathrm{MO}$ evaluado a las 9 semanas post-trasplante que varían entre el $85 \%$ y el $88 \%$, lo que confirma que el que el QR en MO del aloinjerto se produce de forma precoz y es independiente del tratamiento movilizador de $\mathrm{CMMO} \mathrm{CD} 34^{+}$con plerixafor.

Entre otras limitaciones de nuestro estudio encontramos el tamaño muestral, ya que impidió detectar con suficiente potencia diferencias cuya significancia podría haberse alcanzado con un mayor tamaño. Además, el modelo de IS subterapéutica no se corresponde con la práctica clínica de la trasplantología pero permitió la generación de RC e incrementar los mecanismos de daño y regeneración celular.

\section{Conclusiones}

Encontramos disminuida significativamente la expresión de G-CSF, IL-6 e IL-12 en el tejido muscular del aloinjerto en el grupo sometido a tratamiento movilizador de $\mathrm{CMMO} \mathrm{CD}^{3} 4^{+}$con plerixafor.
Las conclusiones obtenidas de los objetivos secundarios son:

- El infiltrado leucocitario cualitativo en el tercio medio del tejido muscular del aloinjerto fue más intenso en el grupo no sometido a tratamiento movilizador de CMMO CD34+ ${ }^{+}$con plerixafor. El infiltrado leucocitario cuantitativo de células CD3, CD20 y CD68 en el tercio medio del tejido muscular del aloinjerto fue superior en el grupo no sometido a tratamiento movilizador de CMMO CD $34^{+}$con plerixafor, mientras que el de células CD4 y CD8 fue superior en el grupo sometido a tratamiento movilizador de $\mathrm{CMMO} \mathrm{CD} 34^{+}$con plerixafor.

- El grado de RC medido como PI fue mayor en los vasos del tercio medio y distal del tejido muscular del aloinjerto en el grupo no sometido a tratamiento movilizador de CMMO CD $34^{+}$con plerixafor, mientras que en los vasos femorales fue mayor en el grupo sometido a tratamiento movilizador de $\mathrm{CMMO} \mathrm{CD}_{34}{ }^{+}$con plerixafor. El grado de RC medido como PPA fue mayor en los vasos del tercio distal del tejido muscular del aloinjerto en el grupo no sometido a tratamiento movilizador de $\mathrm{CMMO} \mathrm{CD} 34^{+}$con plerixafor, mientras que en los vasos femorales y del tercio medio del tejido muscular del aloinjerto fue mayor en el grupo sometido a tratamiento movilizador de CMMO $\mathrm{CD} 34^{+}$con plerixafor.

- El porcentaje de QR en la MO del aloinjerto fue mayor en el grupo sometido a tratamiento movilizador de CMMO CD34+ con plerixafor.

Agradecimientos

A la Dra. Carlota Largo Aramburu y al personal del Servicio de Cirugía Experimental por el mantenimiento del bienestar animal. A la Dra. María Teresa Vallejo Cremades por el procesado de las muestras histológicas. A la Dra. Rosario Madero Jarabo por el análisis estadístico.

\section{Dirección del autor}

Dr. Pedro Bolado Gutiérrez

Servicio de Cirugía Plástica, Reparadora y Quemados

Hospital Universitario La Paz

Paseo de la Castellana 261

28046 Madrid, España.

Correo electrónico: pboladog@gmail.com

Bibliografía

1. Libby P, Pober JS. Chronic rejection. Immunity. 2001, 14(4): 387-397.

2. Unadkat JV, Schneeberger S, Horibe EH, Goldbach C, Solari MG, Washington KM, et al. Composite tissue vasculopathy and degeneration following multiple episodes of acute rejection in reconstructive transplantation. Am J Transplant. $2010 ; 10(2): 251-261$. 
3. Li Y, Zhu Y, Wang J, Wei W, Wu B, Li J. Long-Term Comparison of Rat Model of Chronic Allograft Rejection of Orthotopic Small Bowel Transplantation Induced by Cyclosporine versus Tacrolimus. Transplant Proc. 2013,45(5):1811-1815.

4. Suzuki H, Patel N, Matthews M, DelRossi AJ, Doolin EJ, Hewitt CW. Vascularized bone marrow transplantation: A new surgical approach using isolated femoral bone/bone marrow. J Surg Res., 2000, 89(2):176-183.

5. Muramatsu K, Kuriyama R, You-Xin S, Hashimoto T, Matsunaga T, Taguchi T. Chimerism studies as an approach for the induction of tolerance to extremity allografts. J Plast Reconstr Aesthet Surg. 2008, 61(9):1009-1015.

6. Hartner WC, De Fazio SR, Markees TG, Maki T, Monaco AP, Gozzo JJ. Specific tolerance to canine renal allografts following treatment with fractionated bone marrow and antilymphocyte serum. Transplant Proc. 1987,19(1 Pt 1):476-477.

7. Muramatsu K, Bishop AT. Cell repopulation in vascularized bone grafts. J Orthop Res., 2002, 20(4):772-778.

8. Muramatsu K, Kuriyama R, Taguchi T. Repopulation of donor cells from the recipient following extremity graft: studies using the LACZ transgenic rat. Microsurgery. 2007, 31; 28(4): 279-284.

9. Lataillade JJ, Clay D, Dupuy C, Rigal S, Jasmin C, Bourin P, et al. Chemokine SDF-1 enhances circulating CD34(+) cell proliferation in synergy with cytokines: possible role in progenitor survival. Blood. 2000, 1;95(3):756-768.

10. Okabayashi T, Cameron AM, Hisada M, Montgomery RA, Williams GM, Sun Z. Mobilization of Host Stem Cells Enables Long-Term Liver Transplant Acceptance in a Strongly Rejecting Rat Strain Combination. Am J Transplant., 2011, 1;11(10):2046-2056.

11. Miller J, Mathew J, Garcia-Morales R, Zucker KE, Carreno M, Jin Y, et al. The human bone marrow as an immunoregulatory organ. Transplantation. 1999, 27;68(8):1079-1090.

12. Medawar P. Transplantation of tissues and organs: Introduction. British Medical Bulletin. 1965,1;21(2):97-99.

13. Olthoff KM. Hepatic regeneration in living donor liver transplantation. Liver Transpl. 2003, 9(10 Suppl 2):S35-S41.

14. Baan CC, Weimar W. Intragraft cytokine gene expression: implications for clinical transplantation. Transpl Int. 1998; 11(3):169-180.
15. van Besouw NM, Daane CR, Vaessen LM, Balk AH, Claas FH, Zondervan PE, et al. Different patterns in donor-specific production of T-helper 1 and 2 cytokines by cells infiltrating the rejecting cardiac allograft. J Heart Lung Transplant. 1995, 14(5):816-823.

16. Wu CJ, Lovett M, Wong-Lee J, Moeller F, Kitamura M, Goralski TJ, et al. Cytokine gene expression in rejecting cardiac allografts. Transplantation. 1992, 54(2):326-322.

17. Van HE. In situ expression of cytokines in human heart allografts. American Journal of Pathology. 1996, 21;149(6):19912003.

18. de Mattos AM, Meyer MM, Norman DJ, Bennett WM, Sprague J, Bakke AC. Interleukin-12 p40 m-RNA expression in human kidney allograft biopsies. Transpl Immunol. 1997, 5(3): 199-203

19. Vrtovec B, Haddad F, Pham M, Deuse T, Fearon WF, Schrepfer S, et al. Granulocyte colony-stimulating factor therapy is associated with a reduced incidence of acute rejection episodes or allograft vasculopathy in heart transplant recipients. Transplant Proc. 2013, 45(6):2406-2409.

20. Muramatsu K, Kurokawa Y, You-Xin S, Bishop AT, Doi K. Cell traffic between donor and recipient following rat limb allograft. J Orthop Res. 200, 23(1):181-187.

21. Olthoff KM. Molecular pathways of regeneration and repair after liver transplantation. World J Surg. 2002, 26(7):831-837.

22. Miyake K, McNeil PL. Mechanical injury and repair of cells. Crit Care Med. 2003, 31(8 Suppl):S496-501.

23. Bolado P, Landin L. Effect of reverse chimerism on rejection in clinical transplantation. Ann Plast Surg. 2013, 71(5):615-620.

24. Muramatsu K, Suzuki H, You-Xin S, Hashimoto T, Matsunaga T, Taguchi T. Donor cell repopulation of whole-limb allografts in the rat: detection with green fluorescent protein. Plast Reconstr Surg. 2007,120(1):100-107.

25. Mathes DW, Randolph MA, Bourget JL, Nielsen GP, Ferrera VR, Arn JS, et al. Recipient bone marrow engraftment in donor tissue after long-term tolerance to a composite tissue allograft. Transplantation. 2002, 27;73(12):1880-1885. 